\title{
Color Stability of Phycoerythrin Crude Extract (PECE) from Rhodomonas salina toward Physicochemical Factors
}

\author{
Endar Marraskuranto ${ }^{1,2}$, Tri Joko Raharjo ${ }^{1,3^{*}}$, Rina Sri Kasiamdari ${ }^{1,4}$, Tri Rini Nuringtyas ${ }^{1,4}$ \\ 1Department of Biotechnology, Postgraduate School, Gadjah Mada University, Sleman, DI Yogyakarta, Indonesia \\ ${ }^{2}$ Research and Development Center for Marine and Fisheries Product Processing and Biotechnology, \\ Jalan KS. Tubun Petamburan VI, Slipi, Jakarta Pusat 10260, Indonesia \\ ${ }^{3}$ Department of Chemistry, Faculty of Mathematics and Natural Sciences, Gadjah Mada University, Sleman, \\ DI Yogyakarta, Indonesia \\ ${ }^{4}$ Department of Biology, Faculty of Biology, Gadjah Mada University, Sleman, DI Yogyakarta, Indonesia \\ Article history: \\ Received: 15 January 2019; Revised: 15 Maret 2019; Accepted: 28 May 2019
}

\begin{abstract}
Rhodomonas salina produces Cr-phycoerythrin545 as its designated phycoerythrin (PE) with an absorption maximum at $545 \mathrm{~nm}$ and a shoulder $564 \mathrm{~nm}$. PE has potential to be applied as colorants, pharmaceutical agents, and fluorescent dye tags. The stability of the PE color is influenced by the physicochemical factors of the solution. This study aimed to analyze the color stability of PECE against chemical (ethanol and $\mathrm{pH}$ ) and physical (light and temperature) factors. PECE was prepared from freeze-dried biomass of $R$. salina and was extracted in phosphate buffer solution $(\mathrm{pH}=6.0)$ using a freeze-thaw method in $-25{ }^{\circ} \mathrm{C}(2$ hours $)$ and $4{ }^{\circ} \mathrm{C}(24$ hours $)$. The resulting extract was concentrated and dried in a freeze-dryer. Analyses were conducted using UV-visible and fluorescence spectrophotometer. PECE showed color stability against light of white fluorescent lamp exposure up to 8 hours, temperature exposure up to $40{ }^{\circ} \mathrm{C}$, ethanol solution up to concentration of $20 \%(\mathrm{v} / \mathrm{v})$, and pH range 3.9-8.42. Results from this study can be useful for extraction, purification, and future application of Cr-PE545.
\end{abstract}

Keywords: phycoerythrin, Rhodomonas salina, color stability, light, temperature

\section{Introduction}

Phycoerythrin (PE) is a pigment-protein complex consists of colored phycobilin (PB) attached to polypeptide chain. It is one of phycobiliproteins (PBP) contained in Cyanophyte, Rhodophyte, Glaucophyte, and Cryptophyte cell. PBP is a light harvesting pigment contained in photosynthesis instrument in these organisms. There are three major PBPs distinguished by their spectral properties, i.e. PE $\left(\lambda_{\max }=545-575\right.$ $\mathrm{nm})$, phycocyanin $\left(\mathrm{PC} ; \lambda_{\max }=575-645 \mathrm{~nm}\right)$, and allophycocyanin (APC; $\lambda_{\max }=590-654 \mathrm{~nm}$ ) (Toole \& Allnutt, 2003).

$P E$ is contained in lumenal thylakoid of Rhodomonas salina (Cryptophyta) cell. PE contained in $R$. salina is designated as Cr-PE545 since it has maximum absorbance at $\lambda_{\max }=545 \mathrm{~nm}$ and a shoulder at $\lambda=564 \mathrm{~nm}$ (Toole \& Allnutt, 2003) and it reflected red to pink color. It is the only PBP contained in $R$. salina cell. The color comes from the PB structure which is comprised of an open linier tetrapyrrole attached via disulfide bridge to cysteine residue. CrPE545 has a heterodimer structure of $\alpha_{1} \alpha_{2} \beta \beta$ with a maximum molecular of $66 \mathrm{kDa}$ (MacColl et al., 1999). There are total four PB structure attached to $(\alpha \beta)$ monomer, one 15,16-dihydrobiliverdin (DHBV) molecule on $\alpha$ subunit and three phycoerythrobilin (PEB) molecules on $\beta$ subunit (Glazer \& Wedemayer, 1995).

PBP has been known to have the potential to be used as colorant. Phycocyanin is the only PBP that is already available in the market as food colorant now. In order to meet the requirements as natural colorant, a natural pigment has to have certain properties. Color stability is one of the properties that can be used to assay natural pigments. Linablue ${ }^{\circledR}, a$ blue color PC pigment extracted from Spirulina sp., had been tested for its color stability against

${ }^{*}$ Corresponding author.

E-mail: endar.m@gmail.com 
physicochemical factors, i.e. heat, light, ethanol, and $\mathrm{pH}$ exposure (Anonim, 2012). Physicochemical factors assay has been used to test $P E$ color stability on B-phycoerythrin (B-PE) extracted from red microalgae Porphyridium cruentum and Rphycoeryhtrin (R-PE) from red macroalgae Grateloupia turuturu (Munier et al., 2014). Both B-PE and R-PE shared the same color stability toward physicochemical factors, i.e. light exposure, $\mathrm{pH}$, and heat, because they contained the same chromophore that are PEB and phycourobilin (PUB). However, CrPE545 contained one different chromophore in its structure which is DHBV. Therefore, the color stability of Cr-PE545 toward physicochemical factors might show different behaviours.

The objective of this study was to analyze the color stability of PECE extracted from $R$. salina against physicochemical factors, i.e. light, temperature, ethanol, and $\mathrm{pH}$. This study is beneficial not only to strategies taken in extraction and purification steps, but also to the future application of Cr-PE545.

\section{Material and Methods}

\subsection{Material}

Microalga $R$. salina was obtained from the Institute for Mariculture Research and Fisheries Extension/ IMRAFE, Gondol, Bali, Indonesia. The f/2 medium was produced from mineral salts such as $\mathrm{NaNO}_{3}$, $\mathrm{NaH}_{2} \mathrm{PO}_{4} \cdot 2 \mathrm{H}_{2} \mathrm{O}, \mathrm{FeCl}_{3} \cdot 6 \mathrm{H}_{2} \mathrm{O}, \mathrm{Na}_{2} \mathrm{EDTA} \cdot 2 \mathrm{H}_{2} \mathrm{O}$, $\mathrm{MnCl}_{2} \cdot 4 \mathrm{H}_{2} \mathrm{O}, \mathrm{ZnSO}_{4} \cdot 7 \mathrm{H}_{2} \mathrm{O}, \mathrm{CoCl}_{2} \cdot 6 \mathrm{H}_{2} \mathrm{O}, \mathrm{CuSO}_{4} \cdot 5 \mathrm{H}_{2} \mathrm{O}$, $\mathrm{Na}_{2} \mathrm{MoO}_{4} \cdot 2 \mathrm{H}_{2} \mathrm{O}$. This medium also includes vitamin which composed of thiamine $\cdot \mathrm{HCl}$ (vitamin B1) and cyanocobalamin (vitamin B12). All chemicals were from Merck. Water level 1 is an ICP-MS grade water.

\subsection{Methods}

\subsubsection{Preparation of Rhodomonas salina biomass}

$R$. salina was grown in batch-culture with a working volume of $800 \mathrm{~mL}$. The $R$. salina was cultured in a one litre erlenmeyer, with $0.2 \mu \mathrm{M}$ filtered natural seawater (salinity of $33 \%$ ) with a modified $\mathrm{f} / 2$ medium (Andersen, Berges, Harrison, \& Watanabe, 2005), at optimal growth condition according to Marraskuranto, Raharjo, Kasiamdari, and Nuringtyas (2018). All growth media were sterilized using autoclave at $121^{\circ} \mathrm{C}$ for 15 $\mathrm{min}$. The biomass were harvested by refrigerated centrifugation $\left(10,000 \mathrm{xg} ; 4^{\circ} \mathrm{C} ; 10 \mathrm{~min}\right)$. The biomass were freeze-dried and kept in $-25^{\circ} \mathrm{C}$ freezer prior to use.

\subsubsection{Extraction of PECE}

The extraction of Cr-phycoerythrin545 (Cr-PE545) was performed in accordance to Lawrenz, Fedewa, and Richardson (2011). The dry biomass of $R$. salina was macerated in $0.1 \mathrm{M}$ phosphate buffer solution $(\mathrm{pH}=6.0)$ (22 $\mathrm{mL} / \mathrm{g}$ dry biomass). The solution was subjected to freezing-thawing extraction, freezed at $-25^{\circ} \mathrm{C}$ for 2 hours and left refrigerated for 24 hours. Phycoerythrin-containing supernatant was separated after concentrated in a refrigerated sentrifuge $(10,000$ $\left.\mathrm{xg} ; 4^{\circ} \mathrm{C} ; 10 \mathrm{~min}\right)$. The PECE was dried using a freezedryer and kept in $-25^{\circ} \mathrm{C}$ freezer prior to use.

\subsubsection{Color stability test of PECE}

The PECE color stability test was carried out based on Munier et al. (2014) with some modifications. The dried PECE was dissolved in a universal buffer solution (Solution A: $10.2 \mathrm{~g}$ of citric acid, $6.1 \mathrm{~g}$ of phosphoric acid, $5.6 \mathrm{~g}$ of boric acid, $544 \mathrm{~mL}$ of sodium hydroxide solution (1 mol/L) and enough water to make up $1 \mathrm{~L}$; Solution $\mathrm{B}$ : $\mathrm{HCl} 0.2 \mathrm{~mol} / \mathrm{L}$. This recipe yields a $0.2 \mathrm{M}$ buffer; $\mathrm{pH}=6.0$ ) (Forciniti, 2000). The dried PECE was dissolved in the buffer solution, so that the final concentration of PECE in the solution was $0.5 \mathrm{mg} /$ $\mathrm{mL}$, except for the stability study on ethanol solution and $\mathrm{pH}$.

\subsubsection{PECE stability against light of white fluorescent lamp exposure}

Each PECE solution was exposed to the light of white fluorescent lamp with an intensity of $2400-2500$ lux for 0 (control), 1, 2, 4, 6, 8, 14 and 24 hours. The room temperature of light exposure was maintained at $20-22^{\circ} \mathrm{C}$.

\subsubsection{PECE stability against temperature exposure}

Each PECE solution was stored in a $4{ }^{\circ} \mathrm{C}$ refrigerator (control temperature) and soaked in a water bath at a temperature of 40,60 and $80^{\circ} \mathrm{C}$ for 1 hour. Each experiment was carried out without light exposure.

\subsubsection{PECE stability of ethanol}

Dried PECE was dissolved in ethanol solution with concentrations of $5,10,15,20,30,40$, and $50 \%(\mathrm{v} / \mathrm{v})$ respectively, so that the final concentration was 0.5 $\mathrm{mg} / \mathrm{mL}$. Each experiment was carried out without light exposure. 


\subsubsection{PECE stability of $\mathrm{pH}$}

Dried PECE was dissolved in the universal buffer solution (Forciniti, 2000), with a pH of $3.9 ; 4.27 ; 5.72$; $6.58 ; 7.61 ; 8.42 ; 9.32 ; 10.27$; and 12.52 , so that the final concentration was $0.5 \mathrm{mg} / \mathrm{mL}$. Each experiment was carried out without light exposure.

The color change of each treatment sample was observed based on absorption spectra at wavelength 400-750 nm using a UV-Vis spectrophotometer (Perkin Elmer Lambda 25 UV-Vis Spectrophotometer) and fluorescence emission spectra using a Luminescence spectrophotometer (Perkin Elmer LS45 Luminescence Spectrometer). The estimation of $\mathrm{Cr}$-PE concentration was calculated spectrophotometrically, using Beer and Eshel (1985) Eq. (1).

$\mathrm{PE}(\mu \mathrm{g} / \mathrm{mL})=[((\mathrm{A} 564-\mathrm{A} 592)-(\mathrm{A} 455-592) \times 0.12) \times 0.12] \times 1000(1)$

This is a trichromatic equations to calculate PECE concentration in aqueous extracts. The equation uses measured light absorbance of its aqueous extracts. PECE solutions were measured their light absorption at wavelength of $455,564,592$, and $750 \mathrm{~nm}$. The measurement was also conducted on buffer solution as a blank. The absorbance values obtained from each wavelength measurements were substracted to blank absorbance. Then, the obtained values were substracted to the absorbance value at $750 \mathrm{~nm}$. Finally, the latter values obtained were used in equation (1).

\subsubsection{Statistical analysis}

All analyses were performed in triplicate. Mean and standard deviation $( \pm S D)$ were measured for each experiment. PECE concentration data were tested for normal distribution (Kolmogorov-Smirnoff goodness of fit test). The results were analyzed by one-way analyses of variance (ANOVA) with $p<0.05$, using SPSS 15.0. Least Significant Difference (LSD) post hoc test was performed for in depth analysis of the differences between individual treatment.

\section{Results and Discussion}

\subsection{PECE Stability against Light of White Fluorescent Lamps Exposure}

Figure 1 shows the UV-Vis peak spectra of PECE exposed to light. According to Toole and Allnutt (2003), Cr-PE545 has a typical absorbance peak at a wavelength of $545 \mathrm{~nm}$ and a shoulder at $564 \mathrm{~nm}$. This showed that PECE contains two types of phycobilin $(\mathrm{PB})$, i.e. phycoerythrobilin (PEB; $\lambda_{\max }=545 \mathrm{~nm}$ ) and 15,16-dihydrobiliverdin (DHBV; $\lambda_{\max }=564 \mathrm{~nm}$ ). Compared to the reference spectrum at 0 hour, the duration of time causes the PECE absorbance peak to decrease after 8 hours of exposure to light. This shows that the PECE is still stable until light exposure for 4 hours, since there is no siginificant difference in absorbance (Figure 1) and its concentration up to 4 hours (Figure 2). It could mean that the chromophore attached to Cr-PE545 can still absorb in the same energy level as at 0 hour. Another observation also showed that R-PE and B-PE were stable for up to 8 hours of light exposure (Munier et al., 2014). At 24 hours as compared to control, the absorbance peak of PECE decreased by $4.4 \%$ at $545 \mathrm{~nm}$ and $9,35 \%$ at $564 \mathrm{~nm}$. At this exposure time, the PEB shows more stable than the DHBV, since the Cr-PE545 contained three PEB chromophores attatched to three sites in subunit $\beta$ (Doust et al., 2004). It was shown that the decrement of absorbance at wavelength of $545 \mathrm{~nm}$ (maximum absorption of PEB) was lower than that of wavelength of $564 \mathrm{~nm}$ (maximum absorption of DHBV). At a prolonged duration time (48 $\mathrm{h}$ ), the absorbance of R-PE and B-PE at each peak absorption were also decreased (Munier et al., 2014).

The PECE concentration decreased by $29.6 \pm 0.6 \%$ after exposure for 24 hours compared to its concentration at 0 hour exposure. The PECE concentration was stable to light of white fluorescent lamps exposure up to 4 hours, because the PECE concentration did not change significantly at the interval time (Figure 2; $p>0.05$ ). There were significant differences in PECE concentration due to light exposure between $4,6,8,14$, and 24 hours $(p<0.05)$. Munier et al. (2014) showed that the concentration of R-PE and B-PE decreased by $70 \%$ and $30 \%$, respectively, at exposure time of $48 \mathrm{hrs}$.

The sensitivity of PECE to light leads to the structural level change of PB compounds. At a prolonged duration time light exposure or high intensity light, PB could absorb light with high energy at a shorter wavelength in the UV region, so that the color of PB fades. Rossano, Ungaro, D'Ambrosio, Liuzzi, and Riccio (2003) prove that the R-PE solution of Corallina elongata is increasingly faded due to the tendency of PB loss during observations above 15 days.

In the visible light spectrum, PECE has an absorption maximum at $545 \mathrm{~nm}$ and a shoulder at $564 \mathrm{~nm}$ (Figure 1), while the fluorescence spectrum, PECE shows an intense emission at $585 \mathrm{~nm}$ (Figure 3). Emission of fluoresence spectrum showed that the relative intensity of fluorescence decreases as the duration time of light exposure increases. After $24 \mathrm{hrs,}$ the relative intensity of PECE in the solution decreased by $22.55 \%$. According to Rastogi, Sonani, 


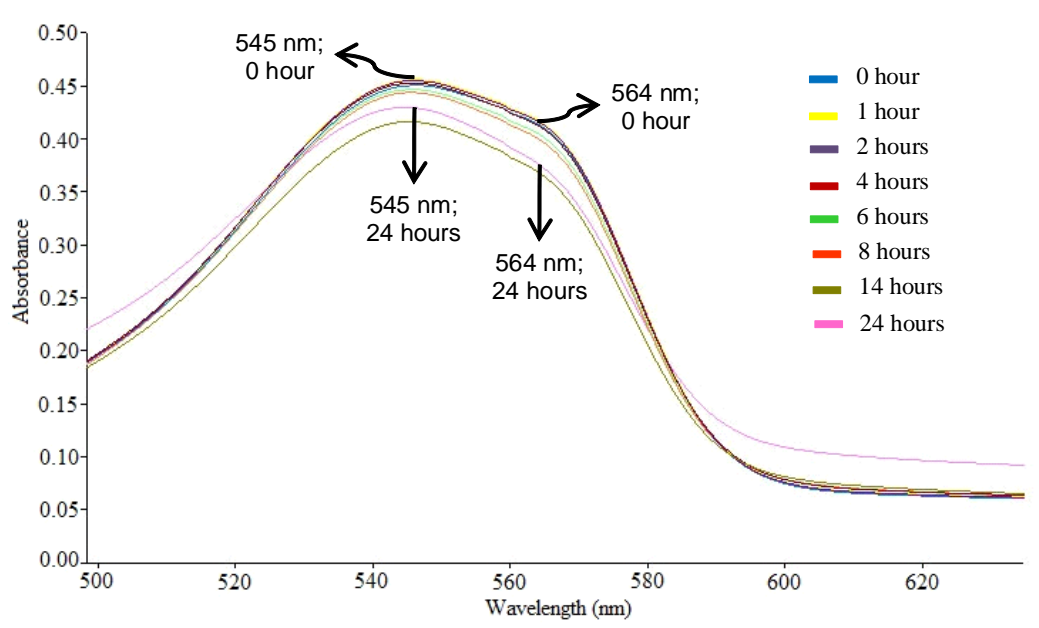

Figure 1. UV-visible spectrum of PECE influenced by light of white fluorescent lamps-exposure

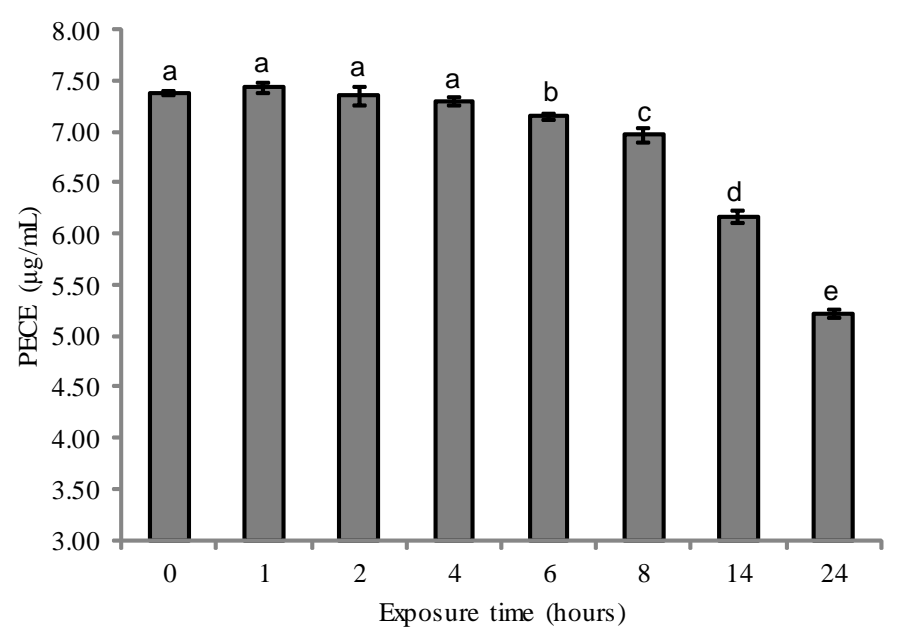

Note: different letters (a-e) showed significant differences $(\alpha=0.05)$

Figure 2. The concentration of PECE influenced by light of white fluorescent lamps-exposure

and Madamwar (2015), fluorescence emission spectrum shows functional properties of PBP.

The calculation of PECE concentration uses wavelength at the visible region, so when the absorbance of PECE decreases at all treatements, eventually the concentration of PECE also decreases. The PECE solution would typically reflect a pink color since it absorb visible light at wavelength of $545 \mathrm{~nm}$. The Cr-PE545 contains two types of PB, i.e. PEB and DHBV. They are an open linier tetrapyrrole that are isomer in structure to each other. The color of PE comes from the existence of conjugated double bond of carbon-carbon and carbon-nitrogen and nitrogen atom in the PB structure. When exposed to light, the intensity and duration of exposure would influence the color of PE. It means that light would influence the most to the chromophore.

\subsection{PECE Stability against Temperature Exposure}

In evaluating PECE color stability, we observed the stability of PECE colors at 40,60 , and $80^{\circ} \mathrm{C}$, with observations at $4{ }^{\circ} \mathrm{C}$ as the control temperature. We wanted to observe the effect of these three temperature points on protein stability which directly affects stability PECE color. Based on UV-Vis spectra, the color of PECE in the solution was still stable at temperature up to $40^{\circ} \mathrm{C}$. The PECE stability began to decrease, which was shown by the fading color of the solution, at temperature of $60^{\circ} \mathrm{C}$. The absorbance value of PECE at $60^{\circ} \mathrm{C}$ decreased by $12.9 \%$, while at temperature of $80^{\circ} \mathrm{C}$, the absorbance value of PECE decreased to $41.9 \%$. The heating temperature of $80^{\circ} \mathrm{C}$ causes PECE to loss its absorbance peaks in UV-Vis spectra (Figure 4). At this temperature, not 


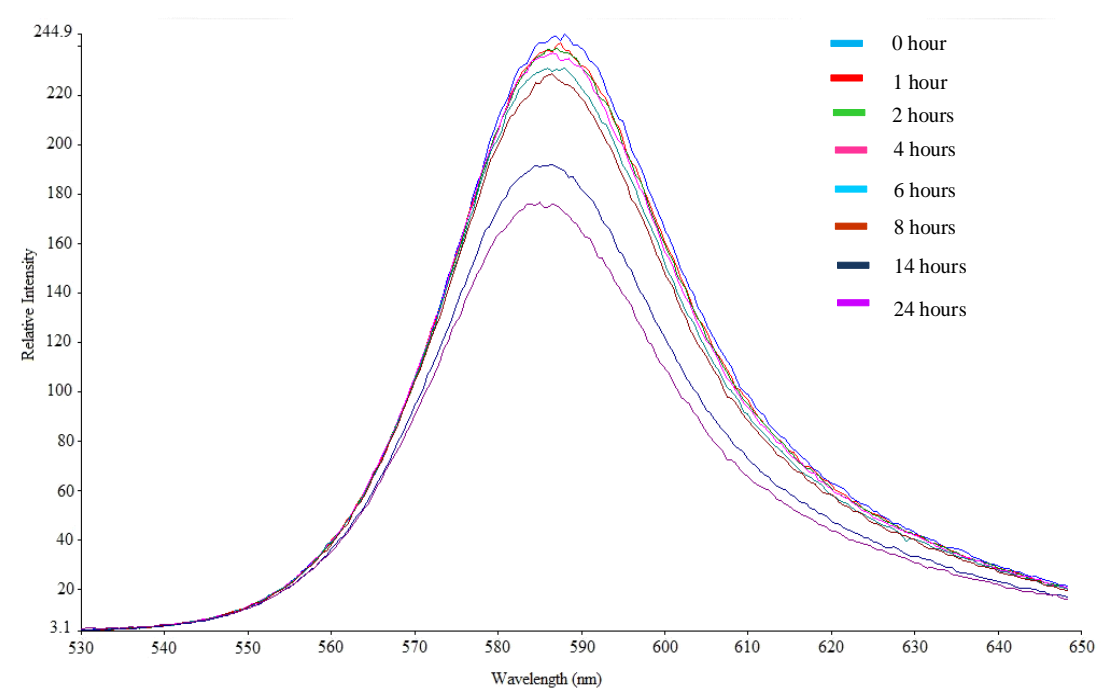

Figure 3. Fluorescence emission spectrum of PECE at different duration times of light of white fluorescent lamps- exposure

only the chromophores of PECE were affected, but also the apoprotein which it will denature. Both R-PE and B-PE also showed no significant change in absorption spectrum up to $40^{\circ} \mathrm{C}$, with a decrease in the intensity at $60^{\circ} \mathrm{C}$ (Munier et al., 2014).

The concentration of PECE also decreased, as a result of decreasing absorbance in UV-Vis spectra, along with the increase of temperature (Figure 5). And obviously, the highest PECE concentration was 0.795 $\pm 0.019 \mu \mathrm{g} / \mathrm{mL}$ at temperature of $4^{\circ} \mathrm{C}$. The PECE concentration was considered not detected at temperature of $80^{\circ} \mathrm{C}$, since its calculation yielded negative. So, the PECE concentration at temperature of $80^{\circ} \mathrm{C}$ was not shown in Figure 5 . Statistically, the $P E$ concentration showed significant differences in all temperature treatments $(p<0.05)$. The concentration of PECE decreased by $11.3 \pm 3.2 \%$ and $27.9 \pm 2.9 \%$ at 40 and $60^{\circ} \mathrm{C}$, respectively.

The relative intensity of PECE was affected by heat temperature, the higher the heat the lower the intensity (Figure 6). PECE still showed its intensity up to $60^{\circ} \mathrm{C}$ heat, although there was a decrease in its intensity at $32.1 \pm 1.2 \%$. At $80^{\circ} \mathrm{C}$, PECE showed a significant decrease in its intensity by $93.3 \pm 0.3 \%$ and could experience denaturation. The same observation also obtained by Rastogi et al. (2015) when C-PE extracted from cyanobacteria Phormidium rubidum A09DM experienced a decrease in fluorescence intensity by $97.34 \%$ at $80{ }^{\circ} \mathrm{C}$. While Patel et al. (2018) showed that $\alpha$ and $\beta$ subunit of CPE from Halomicronema sp. R31DM remained unchanged from SDS-PAGE results at $80^{\circ} \mathrm{C}$. They concluded that the individual chromophore - protein complex was not affected by heat up to $60^{\circ} \mathrm{C}$, although the tertiary structure of C-PE might have disrupted.

\subsection{PECE Stability of Ethanol}

Ethanol is a food grade alcohol. Color stability test of PECE in ethanol can be useful for its use as a colorant in alcoholic beverages. Ethanol also can be used as a precipitant for protein purification. So, the use of ethanol can be useful for Cr-PE545 in its application or purification. Figure 7 shows the UV-Vis absorbance spectrum of PECE dissolved in ethanol at concentrations of $5-20 \%(\mathrm{v} / \mathrm{v})$. UV-Vis absorbance spectrum of PECE dissolved in ethanol solution concentrations of $30-50 \%(\mathrm{v} / \mathrm{v})$ were not seen, because it did not completely dissolve in this concentration range. So, the analysis for these samples was continued. Ethanol affects the solubility of PECE in the water as the ethanol attracts water molecules surrounding the surface of Cr-PE545, consequently protein molecules will clump in the solution. Therefore, spectrophotometric analysis was not conducted when PECE was dissolved in a 30-50 $\%(\mathrm{v} / \mathrm{v})$ ethanol solution. At ethanol concentration of $20 \%$ (v/v), PECE was still shown its color and stable in this solution, although UV-Vis absorbance spectrum showed a decrease at $4.8 \%$. Phycocyanin produced by DIC Corporation shows that it can still dissolve in ethanol up to a concentration of $50 \%$, but its blue color intensity was only under $25 \%$. At $20 \%$ ethanol concentration, the Linablue $\AA$ pigment was able to maintain its color intensity above $75 \%$ (Anon., 2012).

Ethanol solutions with different concentrations affect the solubility of PECE, as a result, the calculated 




Figure 4. UV-visible spectrum of PECE influenced by temperature

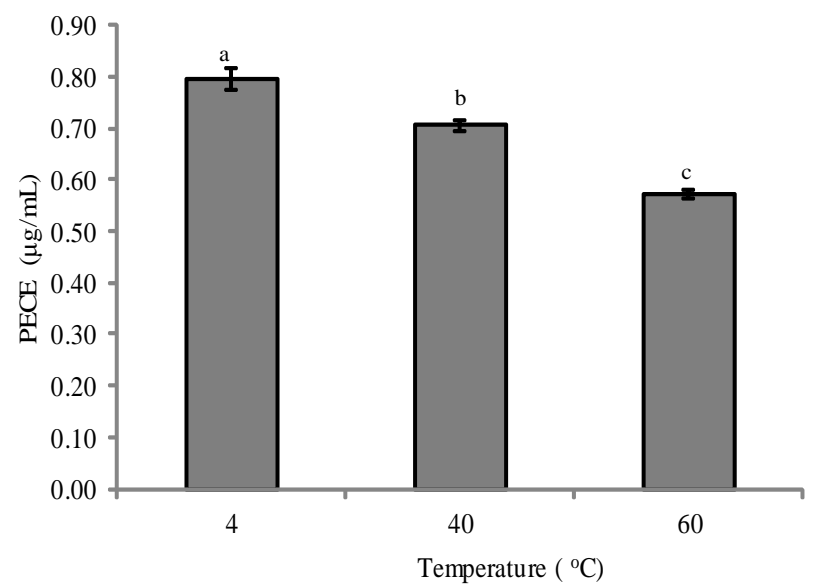

Note: different letters $(\mathrm{a}-\mathrm{c})$ showed significant differences $(\alpha=0.05)$

Figure 5.The concentration of PECE influenced by temperature exposure

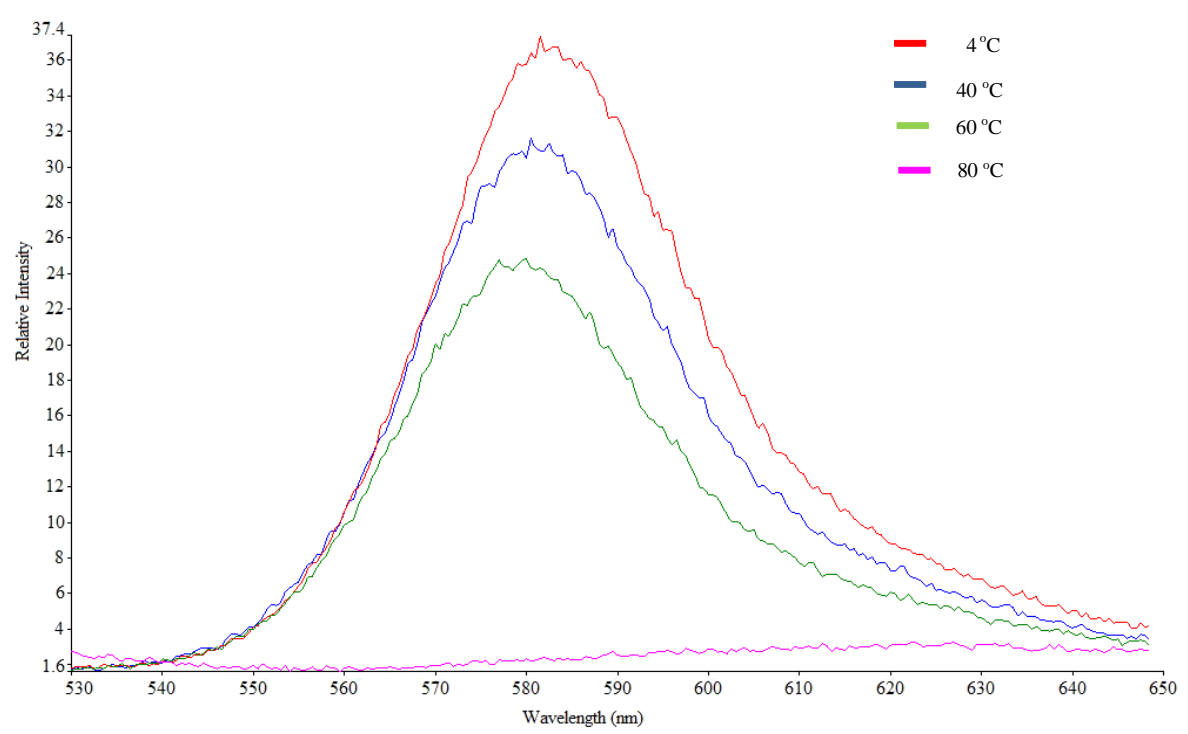

Figure 6. Fluorescence emission spectrum of PECE at different temperature 


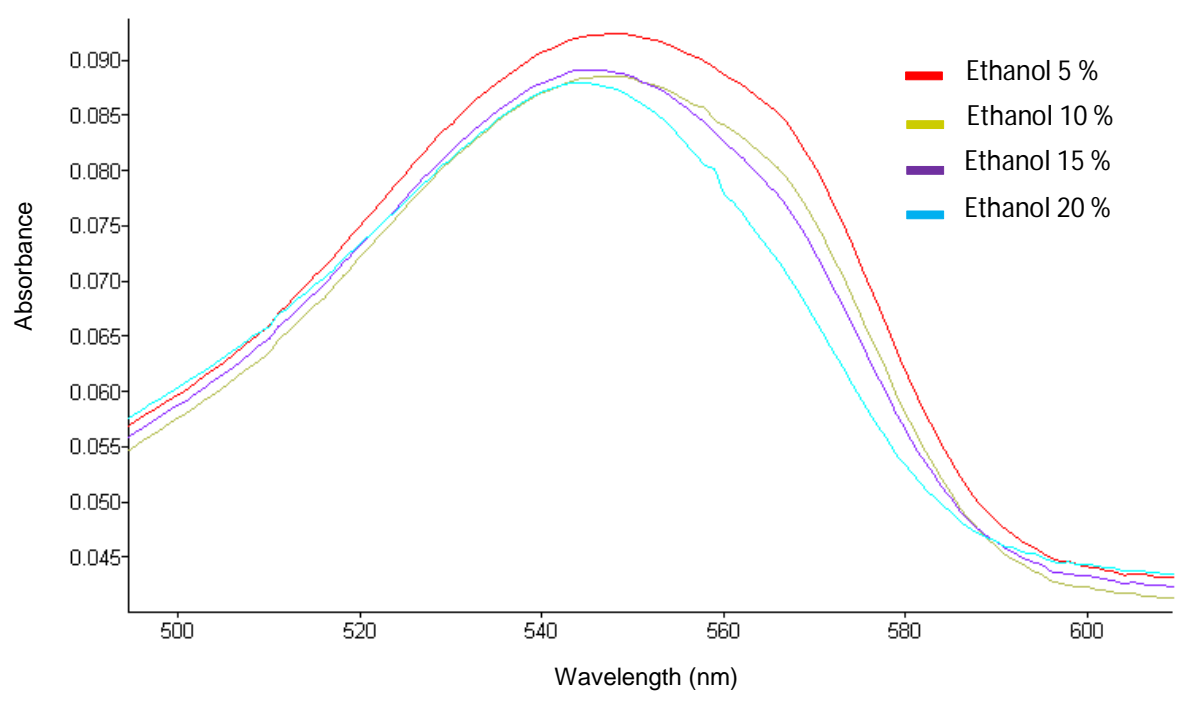

Figure 7. UV-visible peak spectrum of PECE exposed to ethanol

PECE concentration based on the measurement of the absorbance of the solution changes with increasing ethanol concentration (Figure 8). The highest PECE concentration at $5 \%$ ethanol concentration was 0.903 $\pm 0.005 \mu \mathrm{g} / \mathrm{mL}$. The PE concentration showed a significant difference in all treatments $(p<0.05 ; \alpha=$ $0.05)$. In ethanol solution of $20 \%(\mathrm{v} / \mathrm{v})$ concentration, $\mathrm{PE}$ concentration decreased by $34.3 \pm 1.5 \%$. Figure 8 only shows the PECE concentration in ethanol concentration up to $20 \%$. Since dried PECE did not dissolve completely in ethanol concentration of 30$50 \%$, so the concentration calculation was not conducted.

The relative intensity of PECE fluorescence spectrum in $5 \%$ ethanol solution was 41.5 , but its intensity decreased with the increasing ethanol solution concentration (Figure 9). Fluorescence intensity of Cr-PE545 decreased by $9.2,18.3$, and $34.3 \%$ at ethanol concentrations of 10,15 and $20 \%$, respectively.

When PECE was dissolved in ethanol at various concentration, it can only be dissolved partially in ethanol. The higher ethanol concentration, the less PECE was dissolved in ethanol. Ethanol as a polar solvent can cause instability in the natural structure of proteins and reduce protein solubility (Pace et al., 2004). It can be seen from the calculated concentration of PECE as the ethanol concentration rises. The low solubility of protein in ethanol was proven from this study that PECE only soluble in ethanol solutions with a maximum concentration of $20 \%$.

\subsection{PECE Stability of $\mathrm{pH}$}

The stability color of PECE in solutions at various $\mathrm{pH}$ showed that it still retained its color in $\mathrm{pH}$ range 3.9-8.42 based on its absorption spectrum (Figure 10). This shows that the PECE chromophore maintains its structure in that $\mathrm{pH}$ range, so when it shows absorbance peak at visible region, it absorbs visible light. So, the solution will show color. At physiological $\mathrm{pH}(\mathrm{pH}=7.61)$, PECE shows the highest absorbance peak compared to other $\mathrm{pH}$ environment. It shows that it is the most favorable $\mathrm{pH}$ environment for PECE.

Visual observation showed that the PECE solution still appeared pink at pH 3.9, even though the color intensity faded. While at $\mathrm{pH} 9.32-12.52$, the PECE solution looked colorless. The peak absorbance of PECE has decreased by $38,41.1$, and $44.9 \%$ at $\mathrm{pH}$ $9.32,10.27,12.52$, respectively.

Figure 11 shows the effect of various $\mathrm{pH}$ of solutions on PECE concentration. The highest PECE concentration was achieved at $\mathrm{pH} 7.61(1.095 \pm 0.006$ $\mu \mathrm{g} / \mathrm{mL}$ ). The concentration of PECE drastically decreased at $\mathrm{pH} 9.32(90.4 \%)$ and from visual observations of the color of the solution, it was thought that the PECE chromophores had been exposed as a result of the change of apoprotein structure of PECE. The changes of $\mathrm{pH}$ change the the attractions between the groups in the side chains of the apoprotein. Large changes of $\mathrm{pH}$ can cause interference with the electrostatic properties and hydrogen bonds in protein conformation, thus disrupting the structure of the 


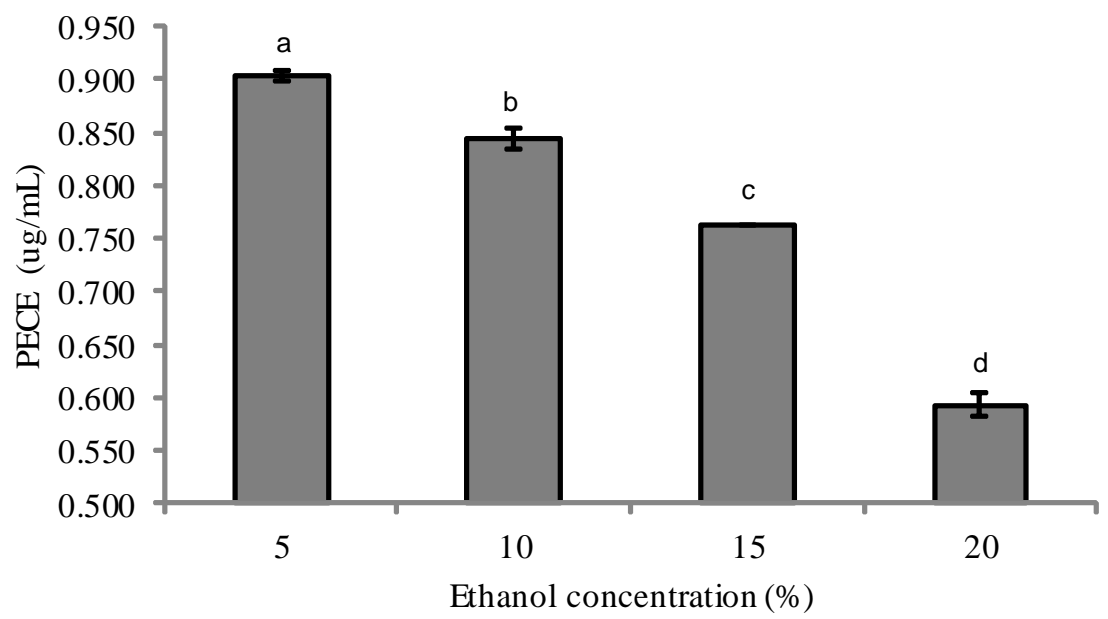

Note: different letters $(a-d)$ showed significant differences $(\alpha=0.05)$

Figure 8. The concentration of PECE influenced by ethanol exposure



Figure 9. Fluorescence emission spectrum of PECE at different ethanol concentration

chromophore (Munier et al., 2014). According to González-Ramírez et al. (2014), changes in the state of protonation on amino acid residues have a large effect on changes in spectral properties of PB. Spectroscopic changes due to low pH may be the result of differences in the state of protonation in the propionate group in the structure of PEB or in the aspartate residues that bind to the group (CamaraArtigas et al., 2012).

At pH 6.58 the concentration of $\mathrm{Cr}$-PE545 showed a different tendency, its concentration decreased after $\mathrm{pH} 5.72$ and increased at $\mathrm{pH}$ 7.61. This condition is thought to be a result of the pl value of Cr-PE545 which is near the $\mathrm{pH}$ of 6.58 and causes a decrease in solubility of Cr-PE545 in the solution and directly decreases the concentration of dissolved Cr-PE545. According to Ogawa et al. (1991), the $\mathrm{pH}$ of the solution affects the modification of protein folding, in condition of acidic pH or close to the value of $\mathrm{pl}$, the protein will be in an aggregated state and its solubility will begin to decrease.

Figure 12 shows the effect of $\mathrm{pH}$ on the fluorescence relative intensity of PECE at a concentration of PECE solution of $0.5 \mathrm{mg} / \mathrm{mL}$. The fluorescence emission at $580 \mathrm{~nm}$ decreased beyond the $\mathrm{pH}$ range $3.9-8.42$. The highest intensity occurred in a pH solution of 7.61 , this could indicate the optimal $\mathrm{pH}$ condition for Cr-PE545 conformation. As in Figure 12 , the intensity of PECE decreased dramatically when PECE was dissolved at pH 9.32 (91.3\%). 


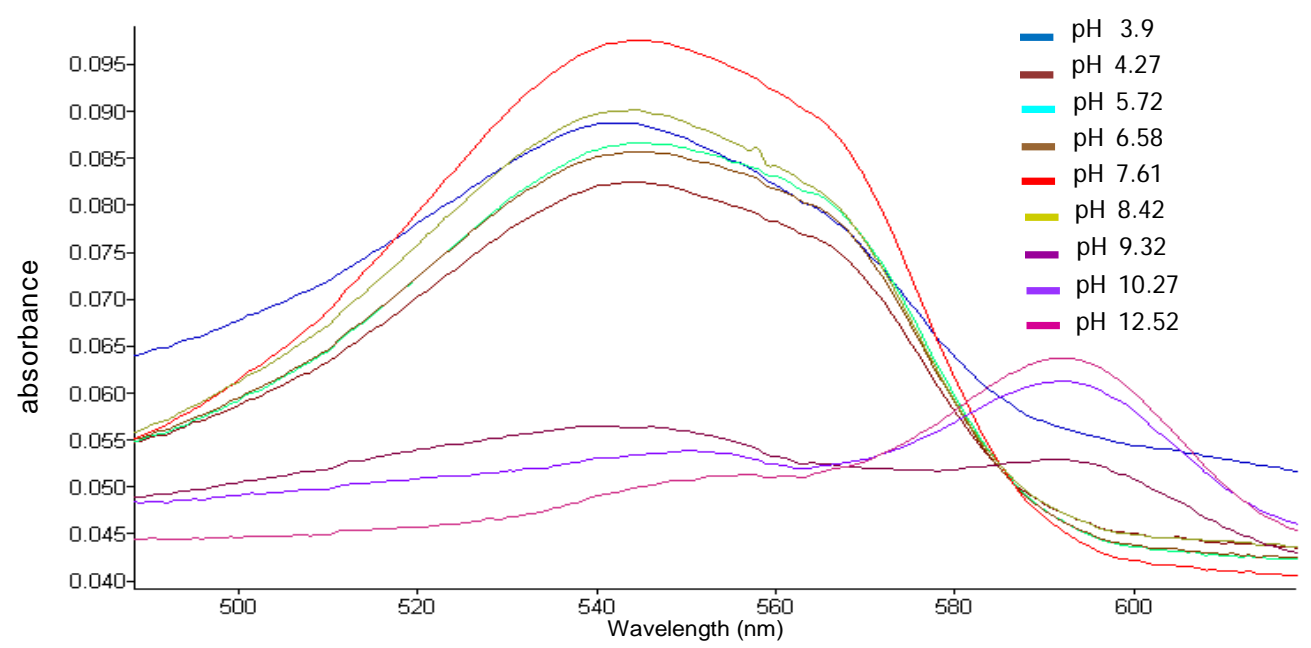

Figure 10. UV-visible peak spectrum of PECE exposed to different $\mathrm{pH}$

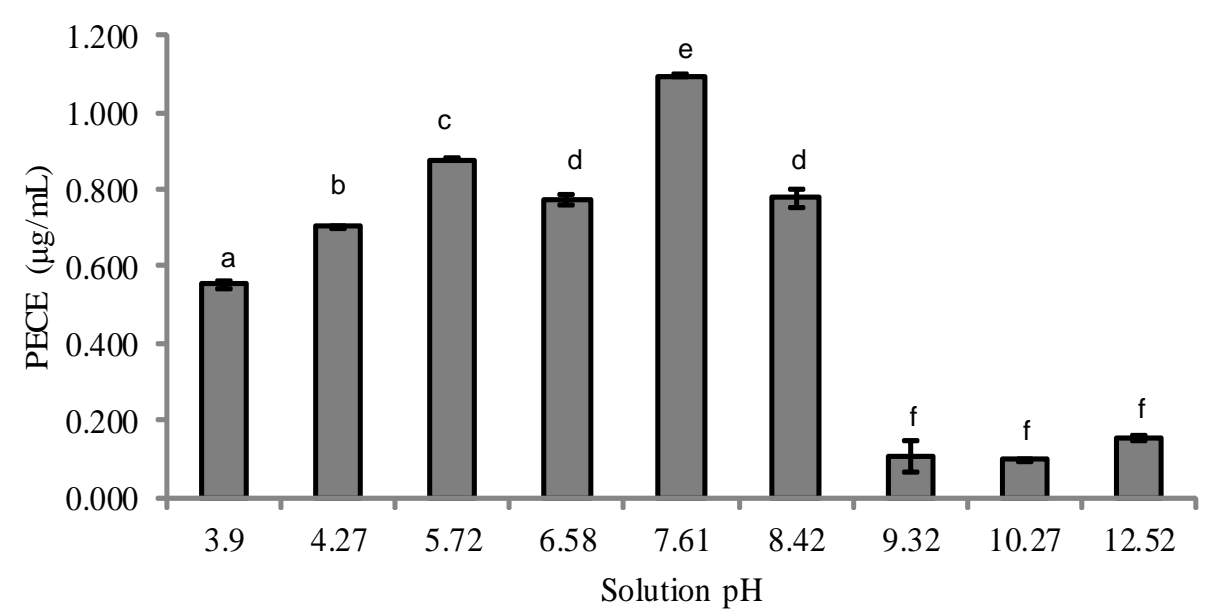

Note: different letters (a-f) showed significant differences $(\alpha=0.05)$

Figure 11. The concentration of PECE influenced by $\mathrm{pH}$ solution

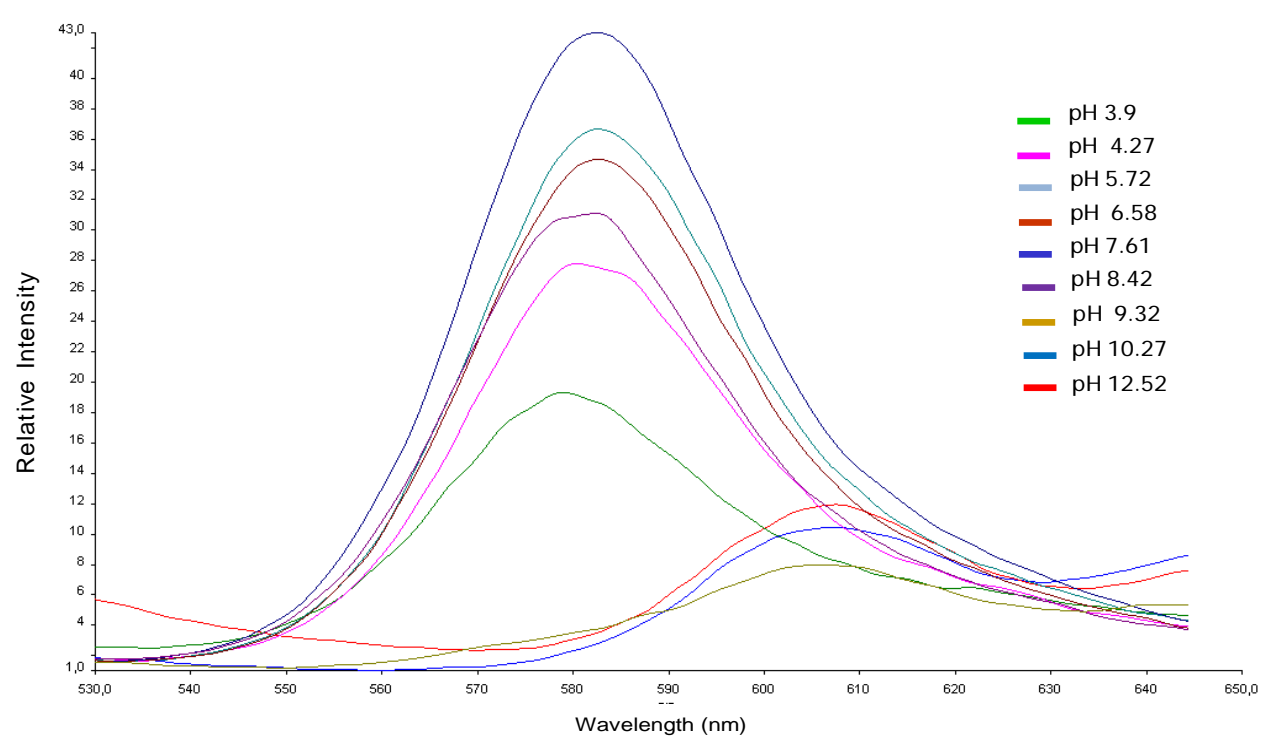

Figure 12. Fluorescence emission spectrum of PECE at different $\mathrm{pH}$ solution 
Different results were obtained by Munier et al. (2014). Both R-phycoerythrin and B-phycoerythrin have fluorescence emission at $575 \mathrm{~nm}$ at the $\mathrm{pH}$ range $4-$ 10. At pH 11, the fluorescence emission of both PEs decreased by $97 \%$.

The interactions between side chains are made up the structure of protein. There are two interactions that are affected by $\mathrm{pH}$ change in the solution, i.e. ionic interactions and hydrogen bonding. Ionic interactions are interactions between positively and negatively charged side chains of amino acids. Increasing the $\mathrm{pH}$ by adding a base converts $-\mathrm{NH}_{3}{ }^{+}$ ion into a neutral $-\mathrm{NH}_{2}$ group, while decreasing the $\mathrm{pH}$ by adding an acid converts the - $\mathrm{COO}$ ion into a neutral $-\mathrm{COOH}$ group. In each case the ionic attractions dissapears, then the protein unfolds. Various amino acids side chains in the protein can form hydrogen bond to each other. Changing the $\mathrm{pH}$ of protein solution would disrupts this bonding and eventually will change the shape of protein (Alberts et al., 2010).

\section{Conclusion}

PECE showed color stability against light of white fluorescent lamps exposure up to 8 hours, heat up to $40^{\circ} \mathrm{C}$, ethanol solution up to concentration of $20-\%$, and $\mathrm{pH}$ range 3.9-8.42. These properties could be useful in handling or further purification of Cr-PE545. Although it can maintain its color up to 8 hours, treatments must be conducted in the dark. For further a application, chemical (ethanol and $\mathrm{pH}$ ) and physical (light and temperature) effect on PECE's color stability could be use as consideration. Compared to R-PE and B-PE, Cr-PE545 showed the same color stability toward light exposure and temperature, however it has narrower range of $\mathrm{pH}$ stability.

\section{Acknowledgment}

This research is funded by the Ministry of Marine Affairs and Fisheries through APBN year 2016. We thank Prof. Dr. Haryanti, MS, from Institute for Mariculture Research and Fisheries Extension (IMRAFE), Gondol, Bali for her donation of $R$. salina cell in 2015.

\section{References}

Alberts, B., Bray, D., Hopkin, K., Johnson, A., Lewis, J., Raff, M., ... Walter, P. (2010). Essential Cell Biology. New York, NY: Garland Science, Taylor \& Francis Group LLC

Andersen, R. A., Berges, J. A., Harrison, P. J., \& Watanabe, M. M. (2005). Recipes for freshwater and seawater media. In R. A. Andersen (Ed.), Algal Culturing
Techniques (pp. 429-538). Oxford, England: Elsevier Academic Press

Anonim. (2012). Linablue® Natural blue colorant derived from DIC Spirulina. Retrieved from http://www.dltspl.co.jp/business/en/spirulina/linablue.html

Beer, S. \& Eshel, A. (1985). Determining phycoerythrin and phycocyanin concentrations in aqueous crude extracts of red algae. Marine and Freshwater Research, 36(6), 785. doi: 10.1071/MF9850785

Borisov, A. Y. (1989). Transfer of excitation energy in photosynthesis: some thoughts, Photosynthesis Research, 20(1), 35-58. Retrieved from https:// www.ncbi.nlm.nih.gov/pubmed/24425463

Camara-Artigas, A., Bacarizo, J., Andujar-Sanchez, M., Ortiz-Salmeron, E., Mesa-Valle, C., Cuadri, C., MartinGarcia, J. M., Martinez-Rodriguez, S., ....Allen, J. P. (2012). pH dependent structural conformations of Bphycoerythrin from Porphyridium cruentum, FEBS Journal, 279, 3680-3691. doi: 10.1111/j.17424658.2012.08730.x

Doust, A. B., Marai, C. N. J., Harrop, S. J., Wilk, K. E., Curmi, P. M. G., \& Scholes, G. D. (2004). Developing a structure - function model for the cryptophyte Phycoerythrin 545 using ultrahigh resolution crystallography and ultrafast laser spectroscopy. Journal of Molecular Biology, (344), 135-153. doi: 10.1016/j.jmb.2004.09.044

Forciniti, D. (2000). Preparation of aqueous two-phase systems. In R. Hatti-Kaul (Ed.), Aqueous two-phase systems: Methods and Protocols (pp. 23-34). New Jersey: Humana Press

Glazer, A. N., \& Wedemayer, G. J. (1995). Cryptomonad biliproteins - an evolutionary perspective. Photosynthesis Research, 46(1-2), 93-105. doi: 10.1007/BF00020420

González-Ramírez, E., Andújar-Sánchez, M., OrtizSalmerón, E., Bacarizo, J., Cuadri, C., MazzucaSobczuk, T., lbáñez, M. J., ....... Martínez-Rodríguez, S. (2014). Thermal and $\mathrm{pH}$ stability of the Bphycoerythrin from the red algae Porphyridium cruentum. Food Biophysics, 9(2), 184-192. doi: 10.1007/s11483-014-9331-x

Lawrenz, E., Fedewa, E. J., \& Richardson, T. L. (2011). Extraction protocols for the quantification of phycobilins in aqueous phytoplankton extracts. Journal of Applied Phycology, 865-871. doi: 10.1007/ s10811-010-9600-0

MacColl, R., Eisele, L.E., Dhar, M., Ecuyer, J-P., Hopkins, S., Marrone, J., Barnard, R., Malak, H., \& Lewitus, A.J. (1999). Bilin organization in cryptomonad biliproteins. Biochemistry. 38: 4097-4105. doi: 10.1021/ bi982059c

Marraskuranto, E., Raharjo, T. J., Kasiamdari, R. S., \& Nuringtyas, T. R. (2018). Influence of salinity on growth and phycoerythrin production of Rhodomonas salina. Squalen Bull. of Mar. and Fish. Postharvest and Biotech., 13(3), 109-114. doi: 10.15578/ squalen.v13i3.365

Munier, M., Jubeau, S., Wijaya, A., Morançais, M., Dumay, J., Marchal, L., Jaouen, P., \& Fleurence, J. (2014). 
Physicochemical factors affecting the stability of two pigments : R-phycoerythrin of Grateloupia turuturu and B-phycoerythrin of Porphyridium cruentum. Food Chemistry, 150, 400-407. doi: 10.1016/ j.foodchem.2013.10.113

Ogawa, H., Mizuno, H., Saito, T., Yamada, Y., Oohusa, T., \& Iso, N. (1991). Effects of $\mathrm{pH}$ on the conformation of phycoerythrin from nori Porphyra sp., Nippon-suisangakkai-shi (Vol. 57). doi: 10.2331/suisan.57.899

Pace, C. N., Treviño, S., Prabhakaran, E., Scholtz, J. M., Franks, F., Wilson, K., Daniel, R. M., Halling, P. J., ....... Purkiss, A. (2004). Protein structure, stability and solubility in water and other solvents. Philosophical Transactions of the Royal Society B: Biological Sciences, 359(1448), 1225-1235. doi: 10.1098/ rstb.2004.1500

Patel, S. N., Sonani, R. R., Jakharia, K., Bhastana, B., Patel, H. M., Chaubey, M. G., Singh, N. K., \& Madamwar, D. (2018). Antioxidant activity and associated structural attributes of Halomicronema phycoerythrin. International Journal of Biological
Macromolecules, 111, 359-369. doi: 10.1016/ j.ijbiomac.2017.12.170

Rastogi, R. P., Sonani, R. R., \& Madamwar, D. (2015). Physico-chemical factors affecting the in vitro stability of phycobiliproteins from Phormidium rubidum A09DM. Bioresource Technology, 190, 219-226. doi: 10.1016/j.biortech.2015.04.090

Rossano, R., Ungaro, N., D’Ambrosio, A., Liuzzi, G. M., \& Riccio, P. (2003). Extracting and purifying Rphycoerythrin from Mediterranean red algae Corallina elongata Ellis \& Solander. Journal of Biotechnology, 101, 289-293. doi: 10.1016/S0168-1656(03)000026

Spear-Bernstein, L. \& Miller, K. R. (1989). Unique location of the phycobiliprotein light-harvesting pigment in the cryptophyceae. Journal of Phycology, 25(3), 412-419. doi: 10.1111/j.1529-8817.1989.tb00245.x

Toole, C. M. \& Allnutt, F. C. T. (2003). Red, Cryptomonad and Glaucocystophyte Algal Phycobiliproteins. In A. W. D. . Larkum, S. E. . Douglas, \& J. A. Raven (Eds.), Photosynthesis in Algae (pp. 305-334). Dordrecht: Kluwer Academic Publishers. 